تعيين مكان مناسب اندازهيرى رطوبت خاك در مديريت آبيارى قطرهاى - نوارى ذرت

زهرا اميرى'، مهدى قيصرى '، محمدرضا مصدقى '، مهسا سادات طباطبايى' و مهرناز مراديانتزاد'

(تاريخ دريافت:

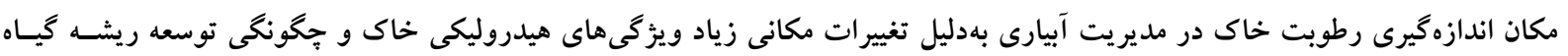

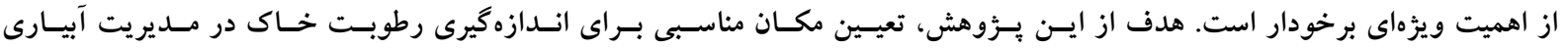

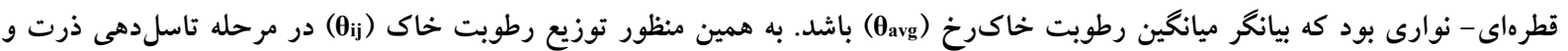

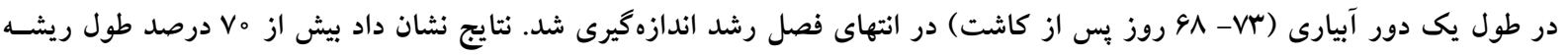

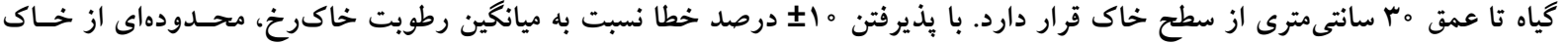

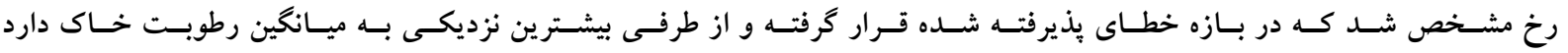

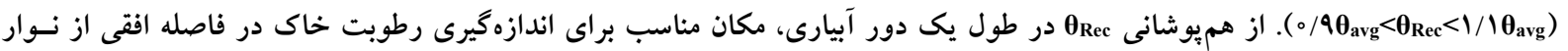

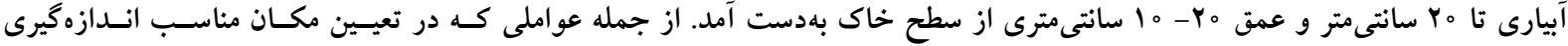

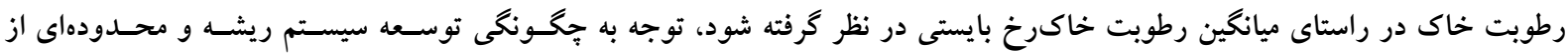

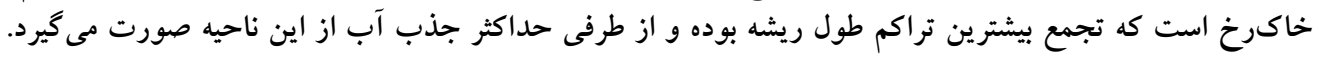

وازههاى كليدى: آبيارى قطرهاى - نوارى، توزيع رطوبت در خاك، توسعه سيسم ريشه، ذرت، ميانگين رطوبت خاكرخ

ا. كروه مهندسى آب، دانشكده كشاورزى، دانشخاه صنعتى اصفهان

r. كروه خاكشناسى، دانشكده كثاورزى، دانشكاه صنعتى اصفهان، اصفهان

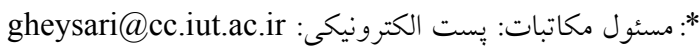




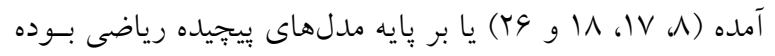

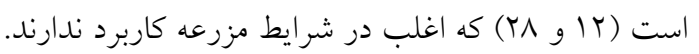

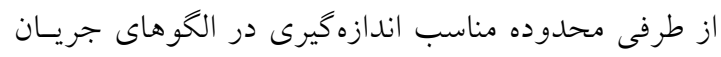

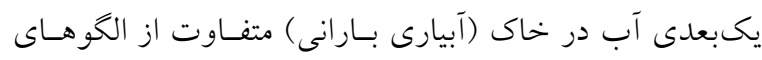

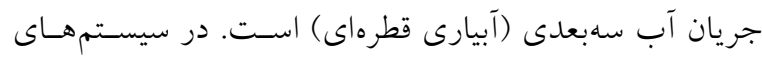

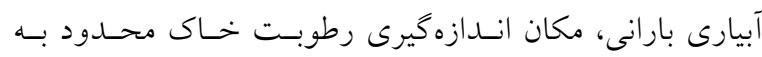

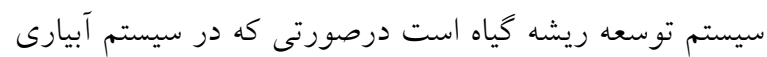

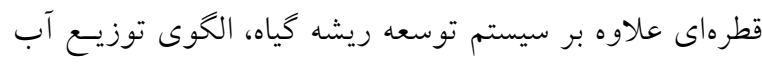

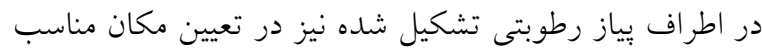

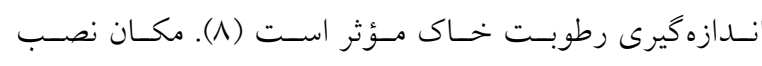
سنسورهاى رطوبتى بهدليل تشكيل الكوى غيريكنواخت توزيع

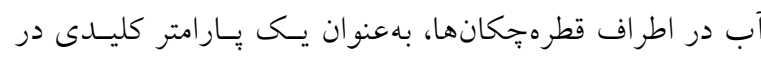

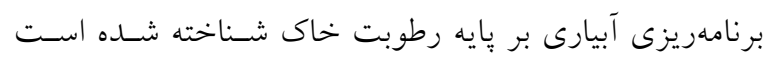

در ايران كمبود منابع آب، توليد محصولات كشاورزى را بـهـ

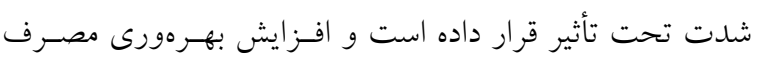

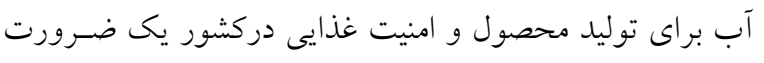

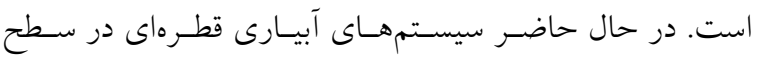

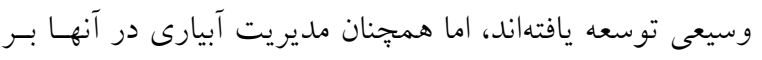

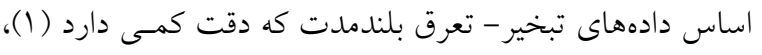

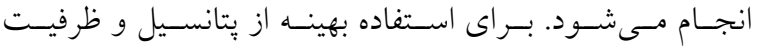

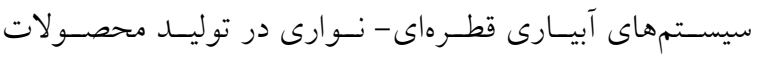

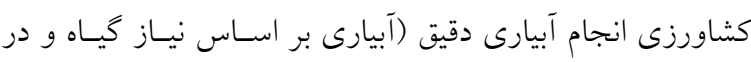

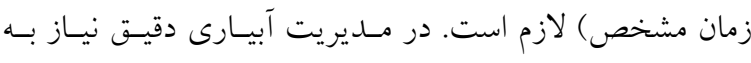

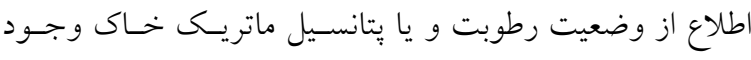

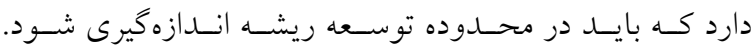

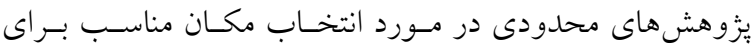

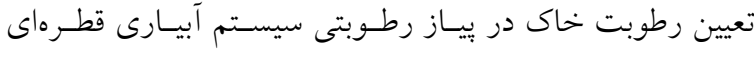

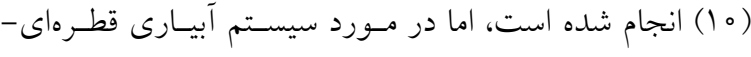

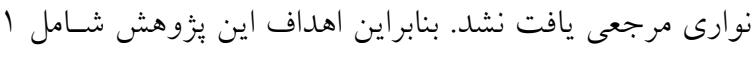

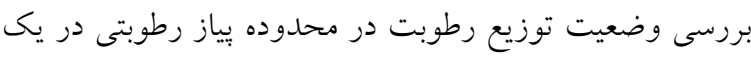

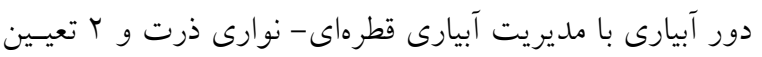

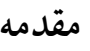

امسروزه افـزايش نيـاز آبـى در بخـشهــاى شهـرى، صـنعت و

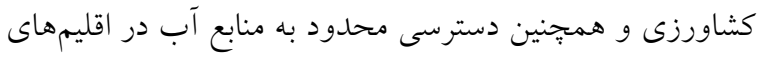

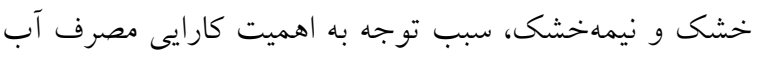

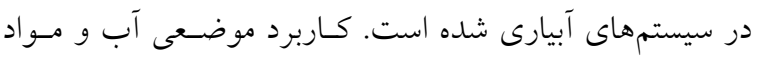

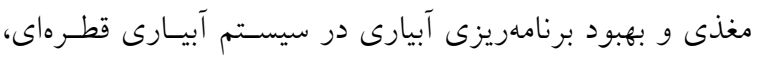

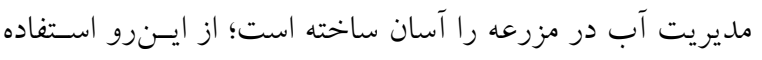

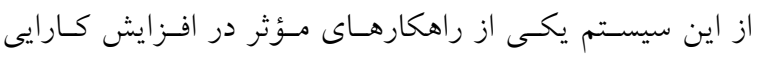

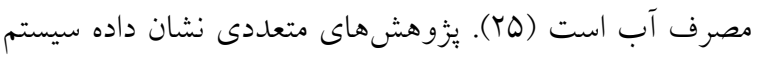

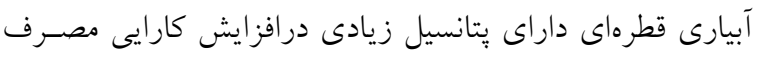

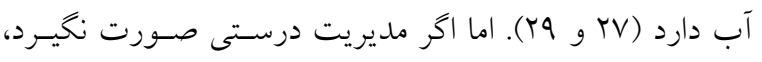
مىتواند سبب هدررفت آب و آبشويى نمكهاى محلول و مواد مواد

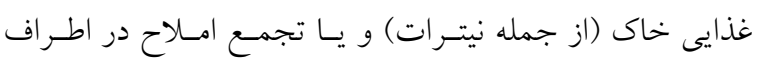

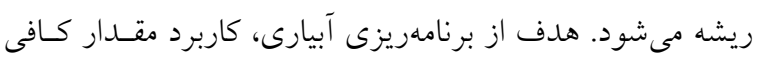

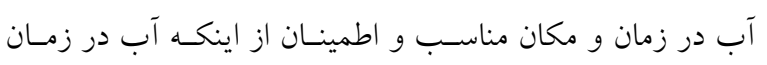

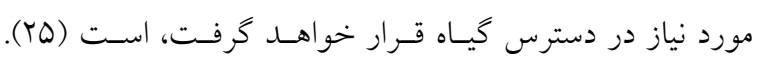

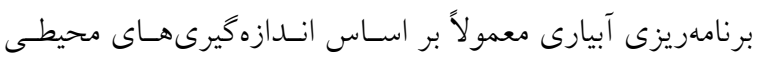
همانند تبخير و تعرق، رطوبت خاى و بررسى تسنش بـ آبسى كيـاه

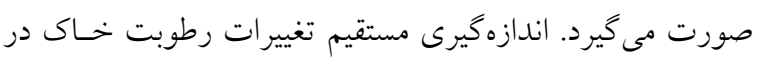

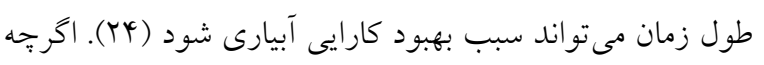

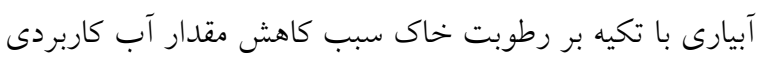

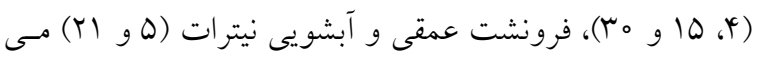

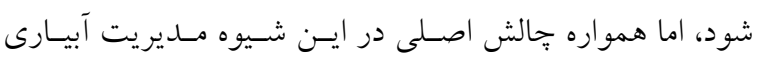

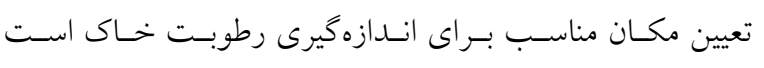

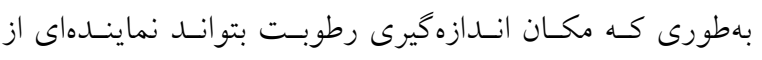

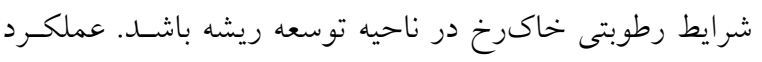

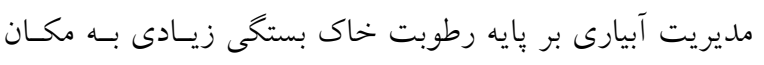
نصب سنسورهاى رطسوبتى دارد (9)، بـهـورى كـه اخـر مكـان مناسبى براى نصب سنسورهاى رطوبتى انتخاب نشود، مىتوانسـ

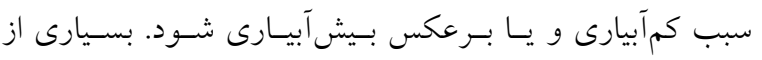

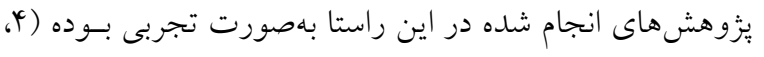

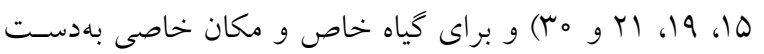




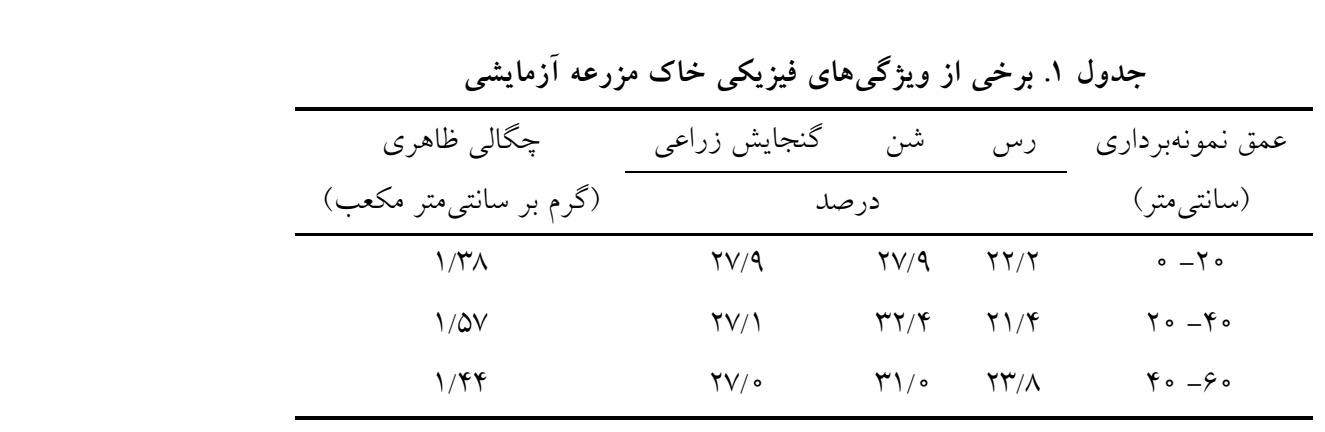

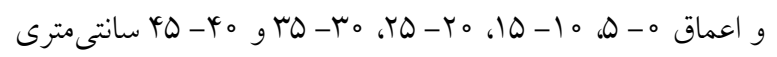

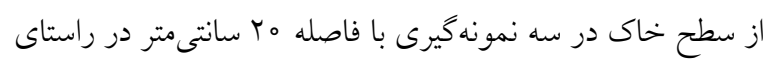
رديف كاشت انجام شد (شكل ا و ؟) و رطوبت خـاك بـه روش وزنى اندازهيرى شد. اندازهيرى رطوبت خاك در نسيمرخ خـاك

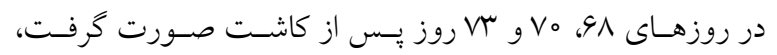
زمانى كه ريشه كياه حداكثر رشد خود را داشته و بيشترين جـذب لَّب

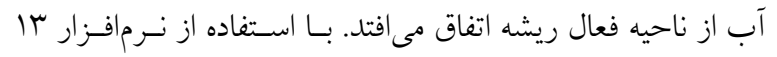
توزيع دوبعدى رطوبت در خاكرخ رسـم شــ و ميـانخين رطوبـت حجمسى (Volume averaged water content, $\theta_{\text {avg }}$ كـل

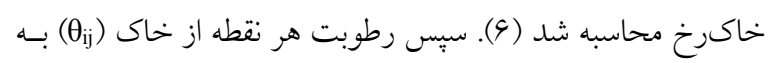
ميانخين رطوبت حجمى خاك تقسيم شد و منحنى رطوبت نسـبى خاى براى تمام روزهاى نمونهبردارى ترسيم شد. با در نظر گرفتن

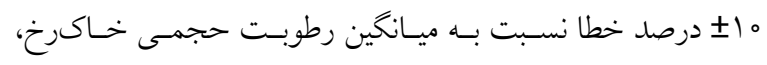
مساحتى از منحنى رطوبت نسبى مشخص شد كـه در بـازه خطـاى يذيرفته شده قـرار مسى گيـــد ( بيشترين نزديكى به ميانخين رطوبت خاك را دارد. مفهوم "مكانهاى معرف يايدار در زمـان" (Time Stable Representative Positions) توسط سوليس و المال كلو در سال 19 Y0 مطرح شد (YY). هــدف از اين مفهوم يافتن موقعيتهاى مكانى از خاكرخ است كـه بتوانسد در طول دور آبيارى براى يَايش رطوبت خاك مناسب باشــــ بـهـ همسين

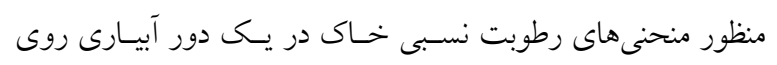
يكديخر قرار كرفتند تا محدوده مناسب در اين يك دور آبيارى تعيين شود. ضريب تغييرات (Coefficient of Variation) رطوبت خاكرخ در روزهاى نمونهبردارى با استفاده از رابطه (1) بهدست آمد. ضريب

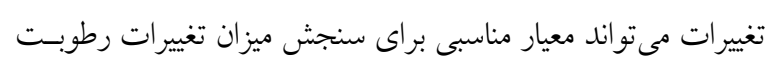
در خاكرخ باشد (10): (1)
محدودهاى از خاكرخ كه بيانخر ميانگين رطوبـت خـاكرخ در بياز رطوبتى سيستم آبيارى قطرهاى-نوارى ذرت باشد، بود.

مواد و روش مها اين يزوهش در مزرعه تحقيقاتى دانشخاه صنعتى اصـفهان واقـع در منطقه لورى (ب0 كيلـومترى جنسوب غربسى شـهر اصـفهان)

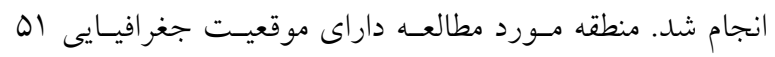
درجه و بr دقيقه طول شـرقى، rr درجسه و rr دقيقـه عـرض شمالى است و در ارتفاع هبوأ مترى از سطح آبهاى آزاد قرار

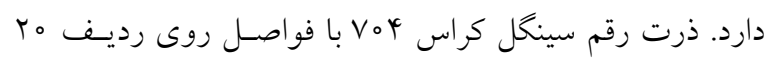
سانتىمتر و بين رديف VQ سانتى متر در تاريخ هفتم تيرماه هوس| كاشته شد و تحت سيستم آبيارى قطرهاى - نوارى، آبيارى شـد.

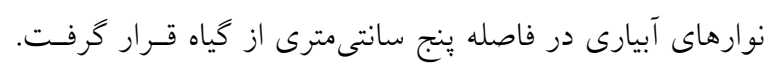

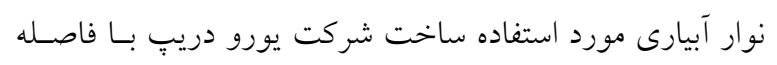

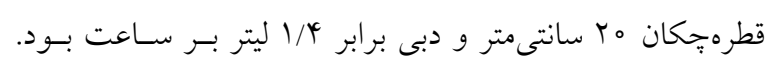

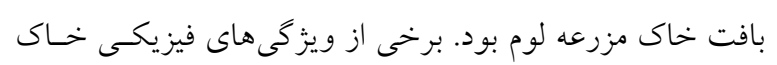
در جدول (1) ارائه شده است. تبخير - تعرق مرجع با استفاده از معادله فائو - يــنمن - مانتيـث

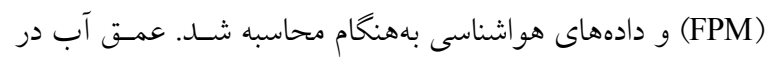

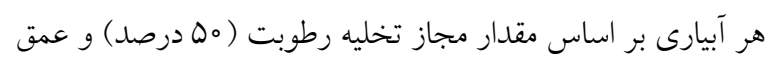

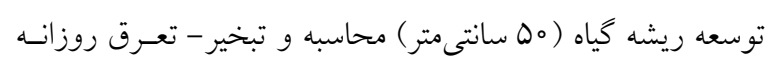
كياه محاسبه شد و با برابر شدن مجموع تبخير - تعرق گياه با مقدار

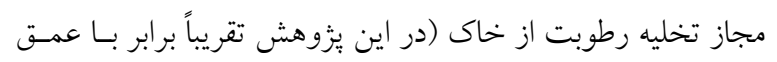
آب در هر آبيارى)، آبيارى بعدى صـورت كرفـت (ع (1). بـهمنظور بررسى حركت آب در خاك، نمونهبردارى با استفاده از استوانههاى

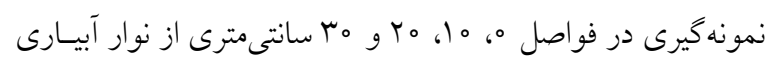


نشر يه علوم آب و خاك (علوم و فنون كشاورزى و منابع طبيعى) / سال بيست و سه / شماره دوم / تابستان لهه|

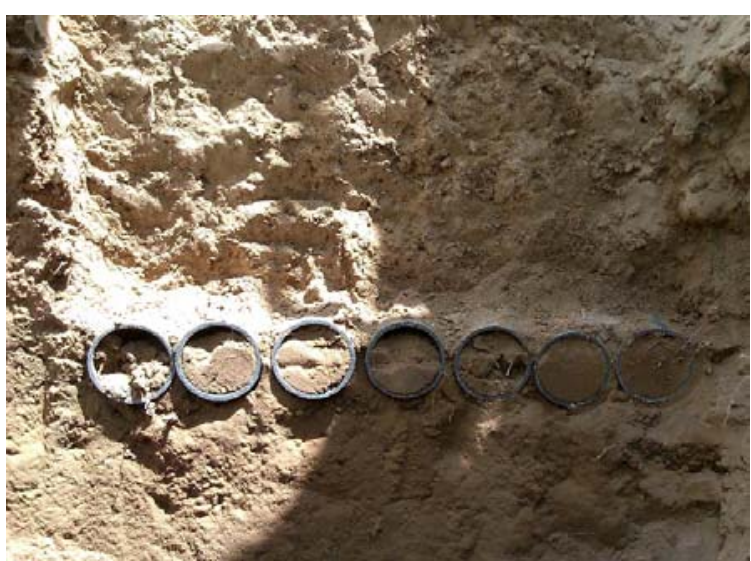

شكل r. نمونهبردارى ريشه از خاكرخ

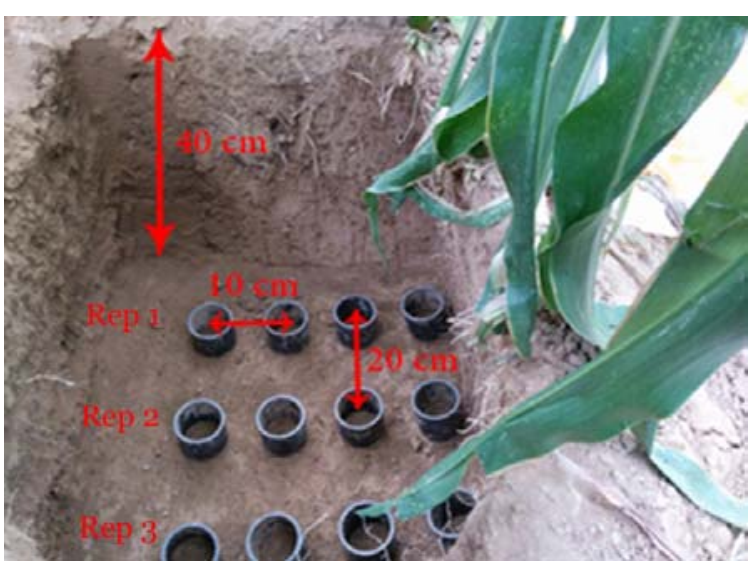

شكل ا. نمونهبردارى از خاكرخ براى اندازهيرى رطوبت خاك

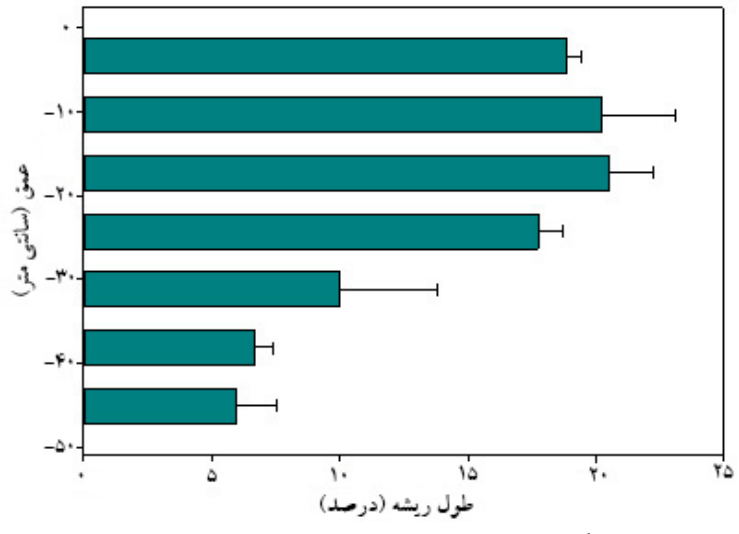

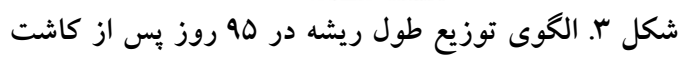

زير قطرهجكان و در عمق ب/ه سانتىمترى از سطح خاك برابـر

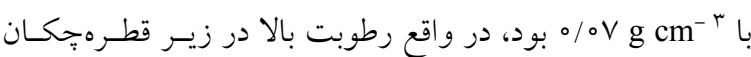

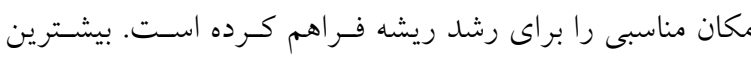

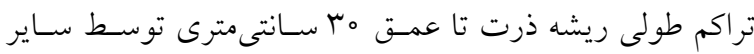

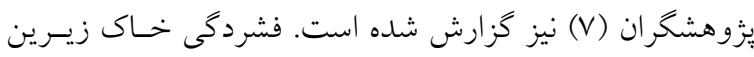
مى تواند سبب رشد سطحى ريشه گياه (تاعمـق ها سـانتىمتر )

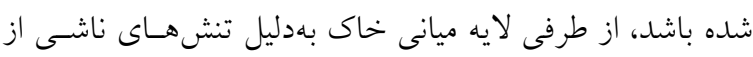

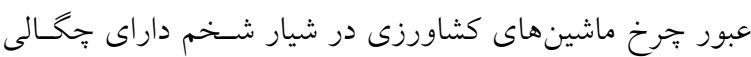

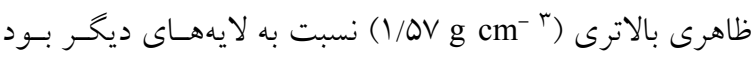

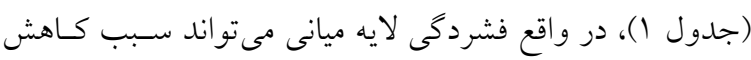

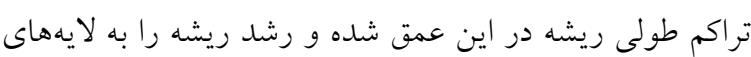

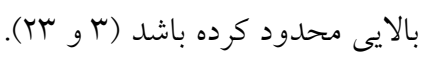

$\mathrm{CV}=\frac{\mathrm{S}}{\theta_{\mathrm{avg}}}$

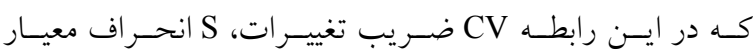
رطوبتهاى اندازهخيرىشــهـ و خاكرخ در يك روز نمونهبردارى است.

\section{نتايج و بحث}

توزيع ريشه در خاكرخ (Root distribution in soil profile)

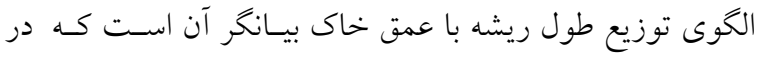

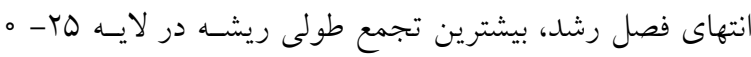

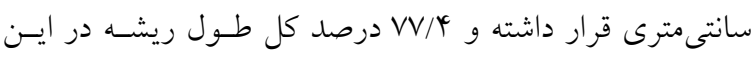

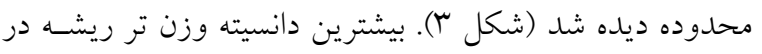




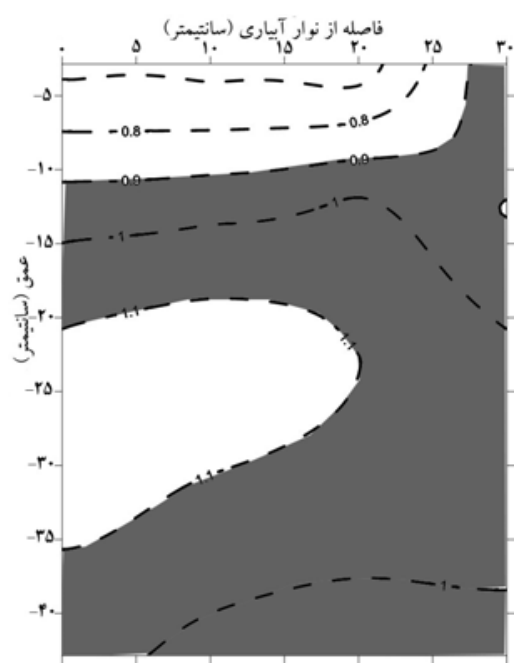

ج

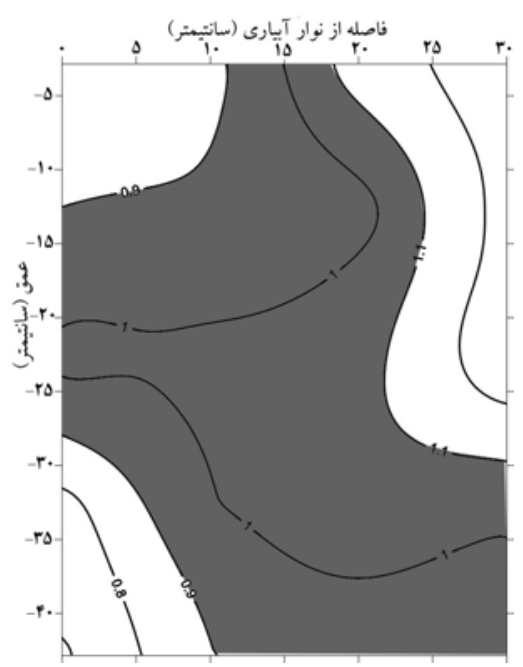

$\varphi$

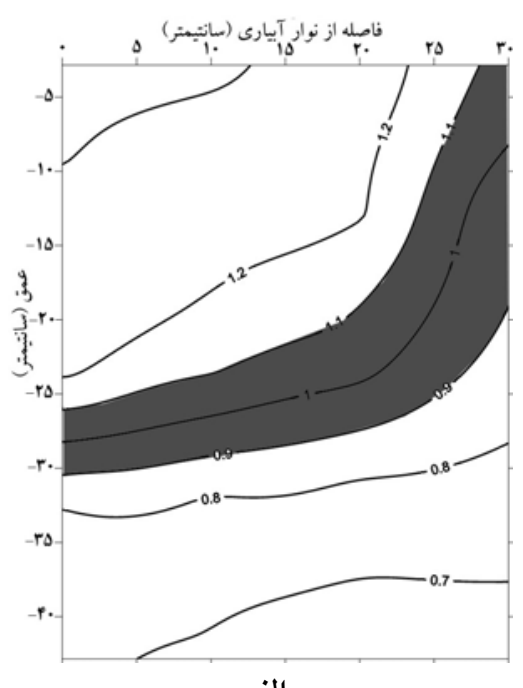

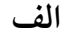

شكل \&. منحنىهاى هممقدار رطوبت نسبى خاك(

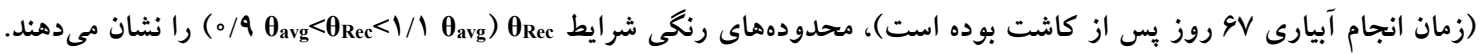

نتايج نشان داد يك روز يّ از آبيـارى ضـريب تغييـرات

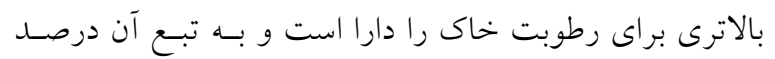

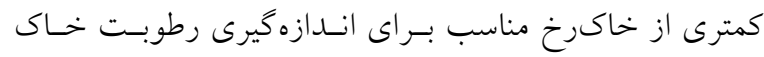

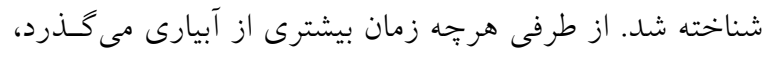

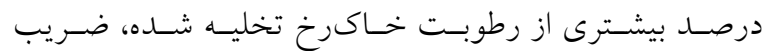

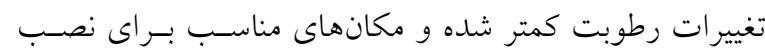

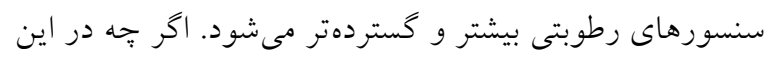

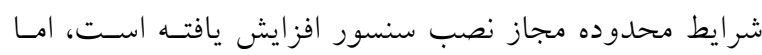

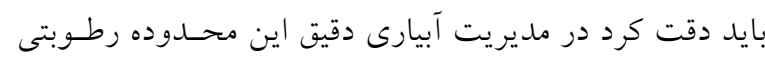

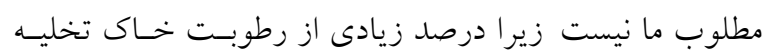
شده است. در مديريت آبيارى دقيق در منطقه توسعسه ريشهـ،

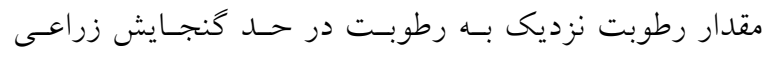

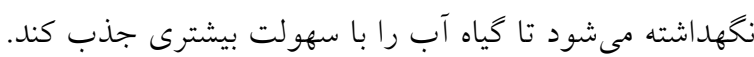

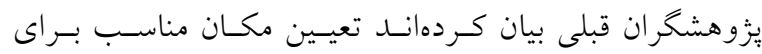

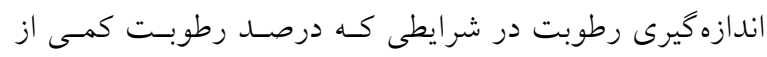
خاى تخليه شده است، اهميت دارد (^).

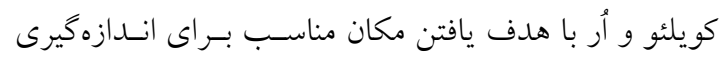
رطوبت خاك با استفاده از مدل نيمهتحليلى در سيسـتم آبيـارى
توزيع رطوبت در خاكرخ (Soil water distribution)

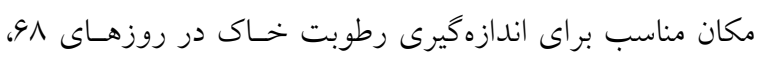

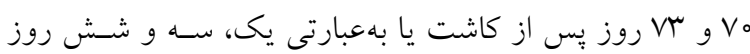

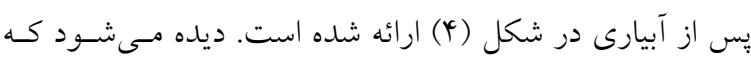
محدوده مناسب براى اندازهيرى

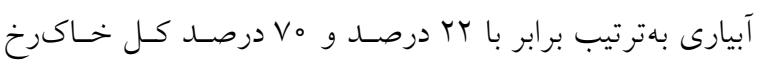

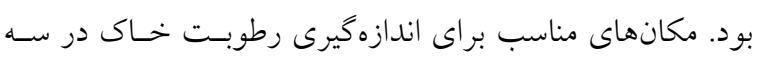

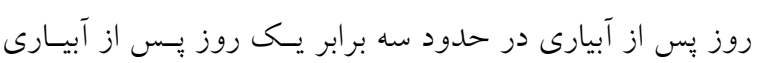

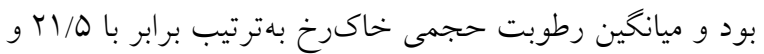

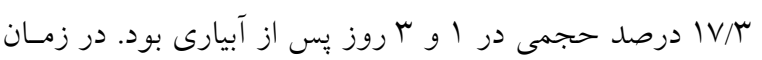

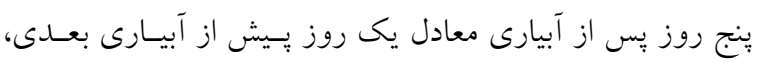
的ec

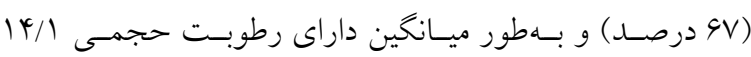

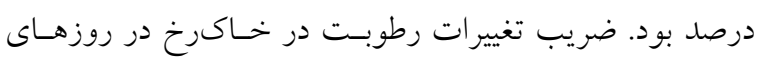

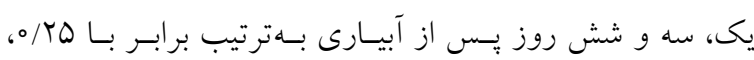

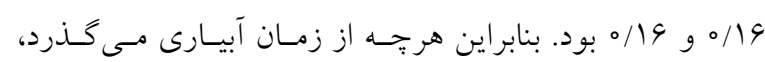
مقدار ضريب تغييرات رطوبت در خاكرخ كاهش يافته و مكان مناسب براى نصب سنسور كستردهتر مىشود. 


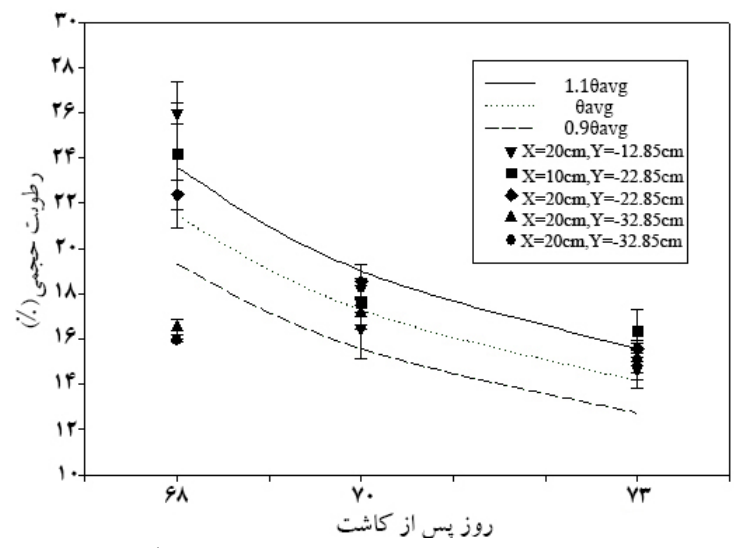

شكل ه. مقايسه رطوبت خاك در نقاط مختلف خاكرخ با با

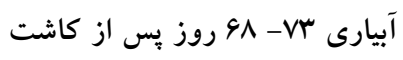

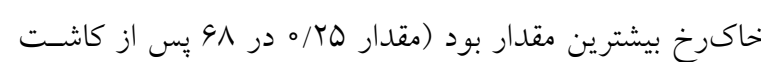

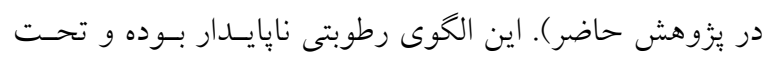

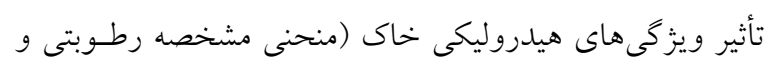

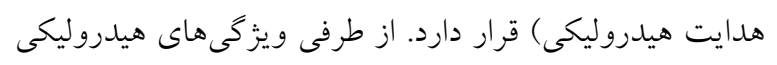

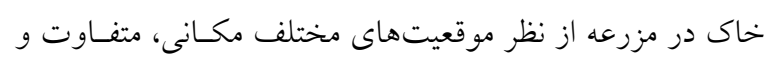

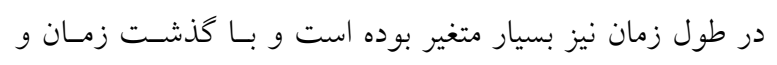

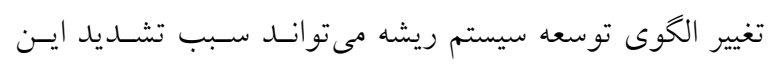

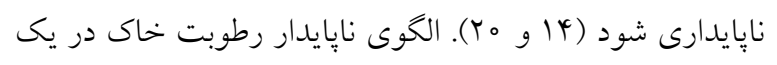

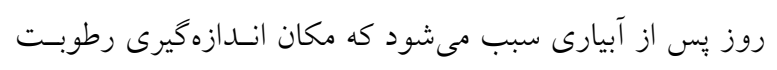

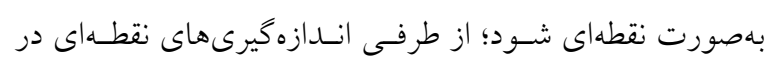

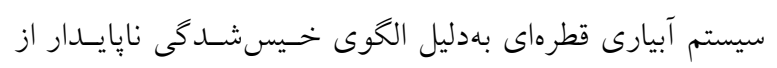

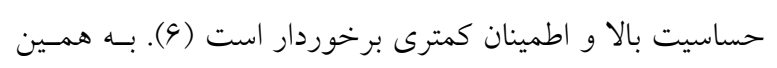

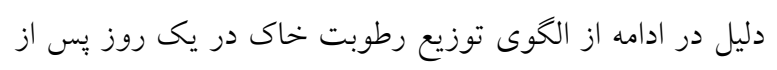

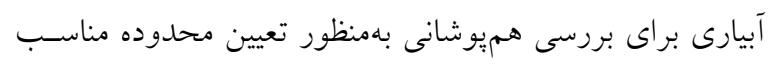

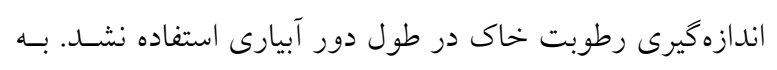

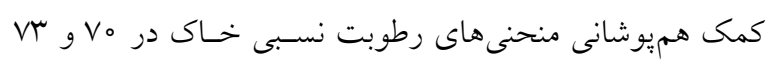

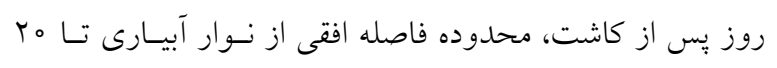

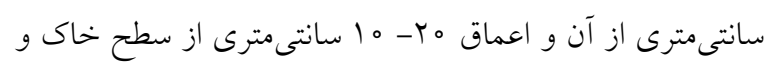

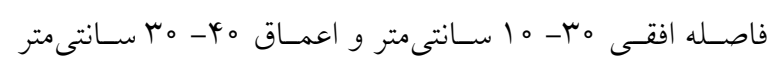

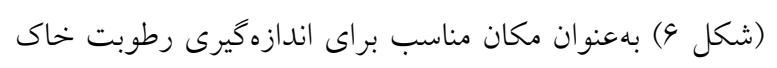

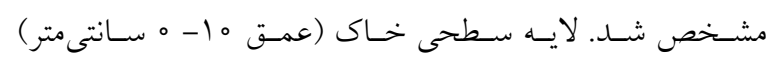

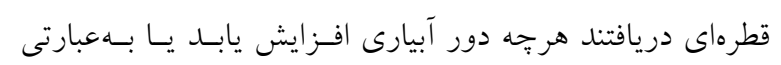

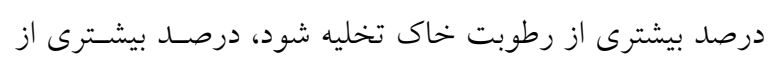

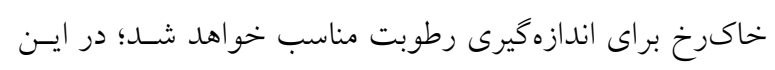

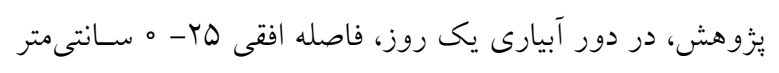

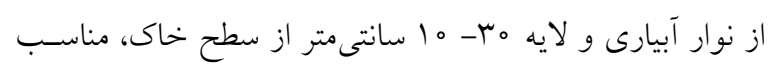

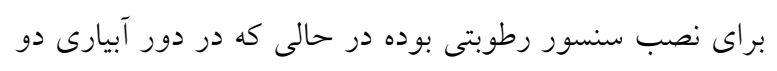

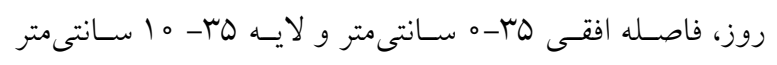
مناسب براى اندازهيرى رطوبت خاى تشخيص داده شد (9). تعيين مكان مناسب اندازهيرى رطويت خاك در طول دور آبيارى

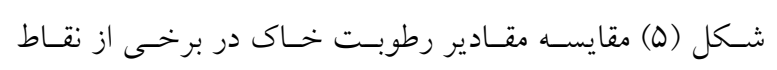

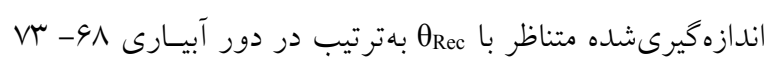

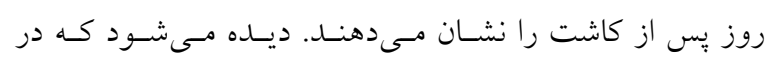
آسارs)

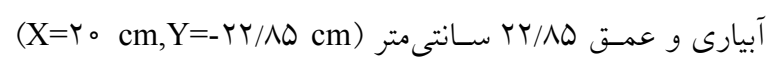

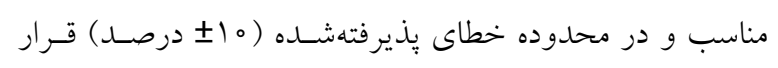

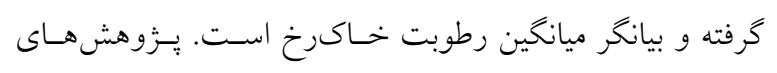

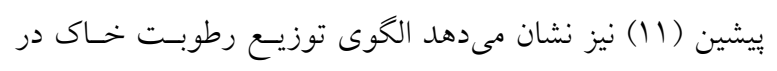

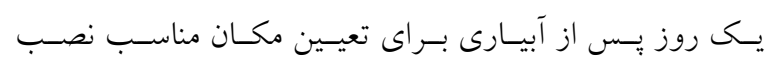

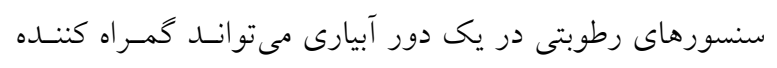

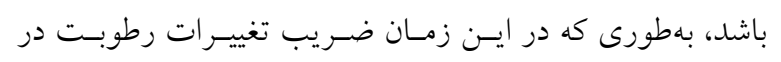




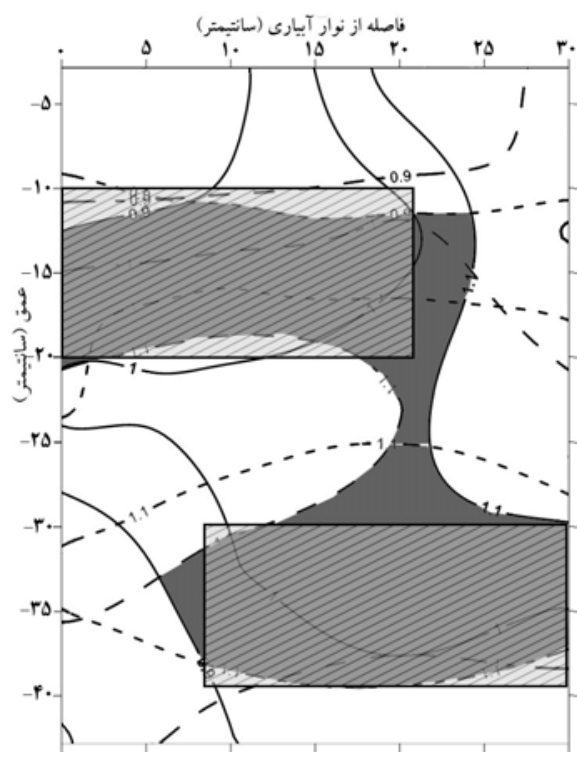

شكل 9. هميوشانى منحنى هاى رطوبت نسبى خاك در محدوده (

نصب قطرهجّان (عمق • إنتى متر) بهدست آوردند، در حالى كه در اين عمق بهدليل شرايط رطوبتى مناسب، بيشـترين تـراكم طولى ريشه ذرت وجود داشت (11).

\section{نتيجه كيرى}

بــــاى انجــام مــديريت آبيــارى دقيـق در سيسـتم آبيــارى قطرهاى-نوارى بر اسـاس انــازهذيرى رطوبـت و يـا يتانسـيل ماتريك خاى در منطقه توسعه ريشـه، عوامـل متعـددى شـامل

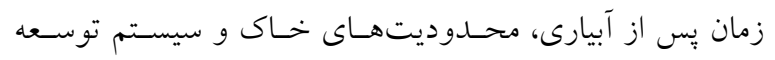
ريشه نقش دارند. مقادير ضـريب تغييـرات رطوبـت در منطقـه

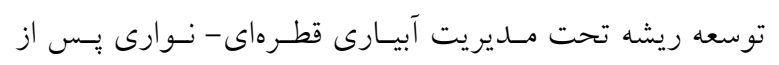

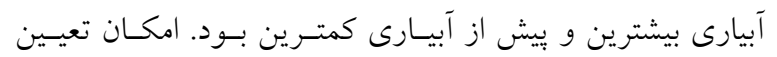

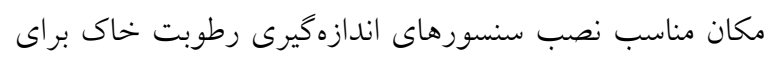
مديريت آبيارى قطرهاى - نوارى بهطورى كه رطوبت آن منطقـه

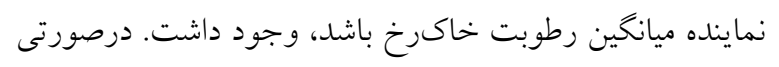
كه دور آبيارى بيش از دو روز باشد، در خـاك بـا بافـت لـوم و

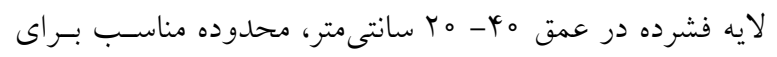

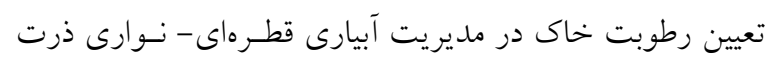

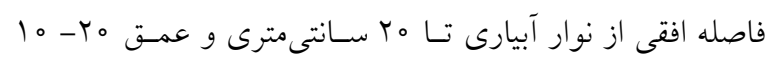

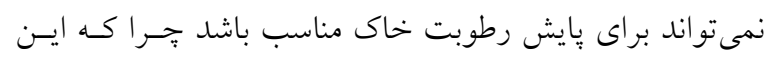

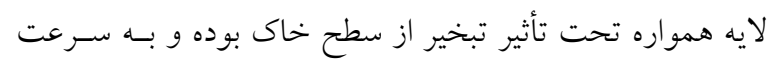
خشك مىشود. بنابراين برنامهريزى آبيارى بر اسـاس تغييـرات

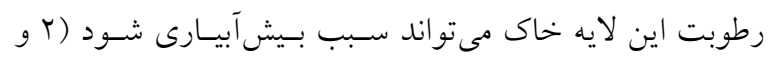
צr). از طرفى نصـب سنسـور در فاصسلههـاى افقـى بيشـتر از o rانتى متر سبب مىشود زمان طولانى ترى نياز باشد تا جبهـه رطوبتى ايجاد شده توسط نـوار آبيـارى در خـاك بـهـ آن مكـان برسد. بنابراين نياز است حجم بيشترى از خاى خــيس شـود و اين بـه معنـاى افـزايش حجسم آب آبيـارى اسـت و در نتيجسه مى تواند مقدار فرونشت عمقى افزايش يابد ( (1).

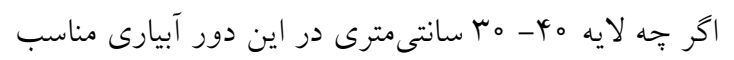
براى اندازهگيرى رطوبت خاك است اما تراكم طـولى ريشـه در اين لايه نسبت به لايههاى سطحى كمتر بوده بهطورى كه بـيش از ه V درصد از كل طول ريشه تـا عمـق ها سـانتى مترى قـرار كرفته است. از اين رو در تعيين مكـان مناسـب نصـب سنسـور توجه به محدوديتهاى خاى و الكوى توسعه ريشـه ضـرورى

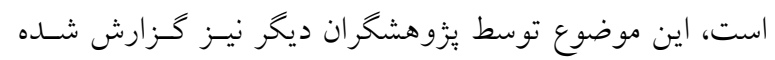

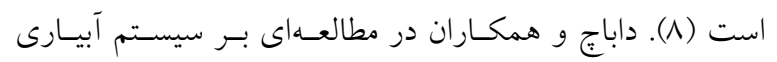
زيرسطحى مكان بهينه براى نصب تانسـيومتر را نزديكىى مكسان 


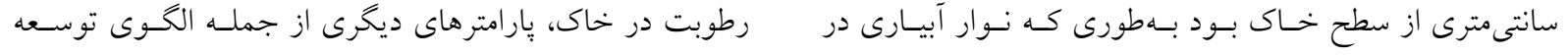

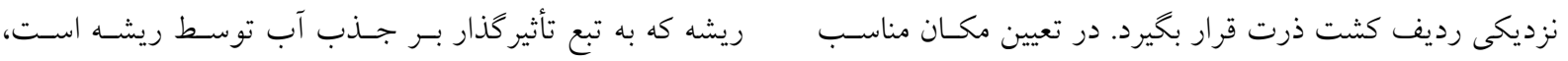

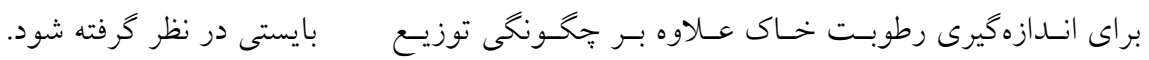

\section{منابع مورد استفاده}

1. Amiri, S., M. Gheysari and B. Movavejalahkami. 2012. Evaluation of efficiency of long-term weather data in trickle and sprinkler irrigation management. Journal of Water and Soil Resources Conversation 2(1): 1-11 (In Farsi).

2. Allen, R. G., L. S. Pereira, D. Raes and M. Smith. 1998. Crop evapotranspiration: Guidelines for computing crop water requirements. FAO Irrigation and Drainage Paper 56. Food and Agriculture Organization, Land and Water, Rome, Italy.

3. Barraclough, P. B. and A. H. Weir. 1988. Effects of a compacted subsoil layer on root and shoot growth, water use and nutrient uptake of winter wheat. Journal of Agricultural Science 110(2): 207-216.

4. Blonquist, J. M., S. B. Jones and D. A. Robinson. 2006. Precise irrigation scheduling for turfgrass using a subsurface electromagnetic soil moisture sensor. Agricultural Water Management 84(1): 153-165.

5. Chighladze, G., A. Kaleita and S. Birrell. 2010. Sensitivity of capacitance soil moisture sensors to nitrate ions in soil solution. Soil Science Society of America Journal 74(6): 1987-1995.

6. Coelho, E. F. and D. Or. 1996. Flow and uptake patterns affecting soil water sensor placement for drip irrigation management. Transactions of the ASAE 39(6): 2007-2016.

7. Coelho, E. F. and D. Or. 1999. Root distribution and water uptake patterns of corn under surface and subsurface drip irrigation. Plant and Soil 206(2): 123-136.

8. Coelho, E. F., D. B. D. Santos and C. A. de Azevedo. 2007. Sensor placement for soil water monitoring in lemon irrigated by micro sprinkler. Revista Brasileira de Engenharia Agrícola e Ambiental 11(1): 46-52.

9. Dabach, S., N. Lazarovitch, J. Šimůnek and U. Shani. 2013. Numerical investigation of irrigation scheduling based on soil water status. Irrigation Science 31(1): 27-36.

10. Dabach, S., U. Shani and N. Lazarovitch. 2015. Optimal tensiometer placement for high-frequency subsurface drip irrigation management in heterogeneous soils. Agricultural Water Management 152: 91-98.

11. Dabach, S., U. Shani and N. Lazarovitch. 2016. The influence of water uptake on matric head variability in a dripirrigated root zone. Soil and Tillage Research 155: 216-224.

12. Dursun, M. and S. Özden. 2017. Optimization of soil moisture sensor placement for a PV-powered drip irrigation system using a genetic algorithm and artificial neural network. Electrical Engineering 99(1): 407-419.

13. Gheysari, M., S. H. Sadeghi, H. W. Loescher, S. Amiri, M. J. Zareian, M. M. Majidi, P. Asgarinia and J. O. Payero. 2017. Comparison of deficit irrigation management strategies on root, plant growth and biomass productivity of silage maize. Agricultural Water Management 182: 126-138.

14. Greenwood, D. J., K. Zhang, H. W. Hilton and A. J. Thompson. 2010. Opportunities for improving irrigation efficiency with quantitative models, soil water sensors and wireless technology. Journal of Agricultural Science 148(1): 1-16.

15. Irmak, S., M. J. Burgert, H. S. Yang, K. G. Cassman, D. T. Walters, W. R. Rathje, J. O. Payero, P. Grassini, M. S. Kuzila, K. J. Brunkhorst and D. E. Eisenhauer. 2012. Large-scale on-farm implementation of soil moisture-based irrigation management strategies for increasing maize water productivity. Transactions of the ASAE 55(3): 881-894.

16. Kiani, M., M. Gheysari, B. Mostafazadeh-Fard, M. M. Majidi, K. Karchani and G. Hoogenboom. 2016. Effect of the interaction of water and nitrogen on sunflower under drip irrigation in an arid region. Agricultural Water Management 171: 162-172.

17. Lei, X., F. Li, S. Zhou, Y. Li, D. Chen, H. Liu, Y. Pan and X. Shen. Spatial variability and lateral location of soil moisture monitoring points on cotton mulched drip irrigation field. In: Proceeding of 2011 International Conference on Computer and Computing Technologies in Agriculture. Springer, Heidelberg, Berlin.

18. Müller, T., P. Perona and R. C. Bouleau. 2016. Optimizing drip irrigation for eggplant crops in semi-arid zones using evolving thresholds. Agricultural Water Management 177: 54-65.

19. Nolz, R. and W. Loiskand1. 2017. Evaluating soil water content data monitored at different locations in a vineyard with regard to irrigation control. Soil and Water Research 12(3): 1-9.

20. Nolz, R., W. Loiskandl, G. Kammerer and M. L. Himmelbauer. 2016. Survey of soil water distribution in a vineyard and implications for subsurface drip irrigation control. Soil and Water Research 11(4): 250-258.

21. Pathan, S. M., L. Barton and T. D. Colmer. 2007. Evaluation of a soil moisture sensor to reduce water and nutrient 
تعيين مكان مناسب اندازهيرى رطوبت خاك در مديريت آبيارى قطرهاى -نوارى ذرت

leaching in turfgrass (Cynodon dactylon cv. Wintergreen). Australian Journal of Experimental Agriculture 47(2): $215-222$.

22. Regen Instruments Canada Inc., 1993-2009. WinRHIZO Pro V.2009b. www.regentinstruments.com.

23. Shierlaw, J. and A. M. Alston. 1984. Effect of soil compaction on root growth and uptake of phosphorus. Plant and Soil 77(1): 15-28.

24. Soulis, K. X. and S. Elmaloglou. 2016. Optimum soil water content sensors placement in drip irrigation scheduling systems: Concept of time stable representative positions. Journal of Irrigation and Drainage Engineering 142(11): $1-9$.

25. Soulis, K. X., S. Elmaloglou and N. Dercas. 2015. Investigating the effects of soil moisture sensors positioning and accuracy on soil moisture based drip irrigation scheduling systems. Agricultural Water Management 148: $258-268$.

26. Stieber, T. D. and C. C. Shock. 1995. Placement of soil moisture sensors in sprinkler irrigated potatoes. American Journal of Potato Research 72(9): 533-543.

27. Tian, D., Y. Zhang, Y. Mu, Y. Zhou, C. Zhang and J. Liu. 2017. The effect of drip irrigation and drip fertigation on $\mathrm{N}_{2} \mathrm{O}$ and $\mathrm{NO}$ emissions, water saving and grain yields in a maize field in the North China Plain. Science of the Total Environment 575: 1034-1040.

28. Wu, X., M. Liu and Y. Wu. 2012. In-situ soil moisture sensing: Optimal sensor placement and field estimation. ACM Transactions on Sensor Networks 8(4): 1-33.

29. Zhang, G., C. Liu, C. Xiao, R. Xie, B. Ming, P. Hou, G. Liu, W. Xu, D. Shen, K. Wang and S. Li. 2017. Optimizing water use efficiency and economic return of super high yield spring maize under drip irrigation and plastic mulching in arid areas of China. Field Crops Research 211: 137-146.

30. Zotarelli, L., M. D. Duke, J. M. S. Scholberg, K. Femminella and R. Munoz-Carpena. 2010. Irrigation scheduling for green bell peppers using capacitance soil moisture sensors. Journal of Irrigation and Drainage Engineering 137(2): 73-81. 


\title{
Determination of the Suitable Location of Soil Moisture Sampling in Drip-Tape Irrigation Management in A Maize Field
}

\author{
Z. Amiri ${ }^{1}$, M. Gheysari ${ }^{*}$, M. R. Mosaddeghi ${ }^{2}$, M. S. Tabatabaei ${ }^{1}$ \\ and M. Moradiannezhad ${ }^{1}$
}

(Received: October 19-2017 ; Accepted: May 12-2018)

\begin{abstract}
Location of soil moisture sampling in irrigation management is of special importance due to the spatial variability of soil hydraulic characteristics and the development of root system. The objective of this study was determination of the suitable location for soil moisture sampling in drip-tape irrigation management, which is representative of the average moisture in the soil profile $\left(\theta_{\text {avg }}\right)$ as well. For this purpose, soil moisture distribution $\left(\theta_{\mathrm{ij}}\right)$ at the tassel stage of maize and one irrigation interval (68-73 day after plant) were measured at the end of season. The results showed more than $70 \%$ length of the root of plant was located in $30 \mathrm{~cm}$ of the soil depth. By accepting $\pm 10 \%$ error in relation to the averaged soil moisture, some region of soil profile was determined which was in the acceptable error range and also near the averaged soil moisture $\left(0.9 \theta_{\mathrm{avg}}<\theta_{\mathrm{Rec}}<1.1 \theta_{\mathrm{avg}}\right)$. By overlapping $\theta_{\mathrm{Rec}}$ in one irrigation interval, the appropriate location for soil moisture sampling was the horizontal distance from drip-tape line to $20 \mathrm{~cm}$ and the depth of $10-20 \mathrm{~cm}$ from the soil surface. To determine the appropriate place for soil moisture sampling, the development of root system and the maximum concentrated root length density in the soil profile extracting the maximal soil moisture should be taken in to account, parallel with the averaged soil moisture.
\end{abstract}

Keywords: Drip-tape irrigation, Soil moisture distribution, Root system development, Maize, Averaged soil moisture of the soil profile

1. Water Engineering Department, College of Agriculture, Isfahan University of Technology, Isfahan, Iran.

2. Soil Science Department, College of Agriculture, Isfahan University of Technology, Isfahan, Iran.

*: Corresponding Author, Email: gheysari@cc.iut.ac.ir 